\title{
La experiencia de apertura financiera en Argentina, Brasil y México
}

\section{María Cristina Penido de Freitas}

Doctora en Economía

por la Universidad

de París XIII e investigadora

de la Fundación de

Desarrollo Administrativo

de la Universidad de São Paulo

cpenido@fundap.sp.gov.br

\section{Daniela Magalhães \\ Prates}

Aspirante al doctorado

en economía por el

Instituto de Economía de la

Universidad de Campinas,

profesora de la

Universidad Paulista

e investigadora de la

Fundación de Desarrollo

Administrativo de la

Universidad de São Paulo

dprates@fundap.sp.gov.br
Este artículo pretende analizar los efectos de la globalización sobre los sistemas financieros de Argentina, Brasil y México, países que recibieron la mayor parte de la inversión extranjera en la región en el decenio de 1990. Esos capitales estaban formados en su mayor parte por flujos de cartera y por adquisición de acciones de los sistemas financieros locales. El movimiento no fue homogéneo, debido a los diferentes grados de apertura y las políticas macroeconómicas adoptadas. En lo que toca a las inversiones de cartera, los efectos de la apertura se concentraron en segmentos distintos y por ello tuvieron impactos diferenciados sobre los sistemas financieros. Las experiencias recientes de esos países muestran que todavía hay espacio de maniobra para las políticas económicas nacionales en el contexto de la globalización financiera, aunque sea limitada la capacidad de esas políticas para atenuar los efectos perversos de las corrientes financieras. En función de la apertura de los sistemas financieros locales, se advierte la importancia creciente de las instituciones extranjeras en los países analizados. Esa tendencia deriva de las medidas de liberalización adoptadas para hacer viable la capitalización de los sistemas bancarios, así como de las estrategias de competencia de los bancos que intentan captar nuevas fuentes de utilidades y fortalecer su posición en los mercados globalizados. El predominio de las instituciones extranjeras, aunque se traduzca en una mayor solidez patrimonial de los sistemas bancarios nacionales, puede tener un impacto macroeconómico adverso, sobre todo en México y Brasil, que todavía conservan una relativa soberanía monetaria. 


\section{I}

\section{Introducción}

En este artículo se pretende analizar los efectos de la globalización sobre los sistemas financieros de Argentina, Brasil y México, países que recibieron la mayor parte de los capitales extranjeros invertidos en América Latina desde comienzos del decenio de 1990. En el contexto del retorno de las corrientes voluntarias de capital hacia la región, se advierte una intensificación de las inversiones extranjeras en los mercados financieros nacionales. Se trata principalmente de corrientes de cartera, es decir, de compra de activos mobiliarios por inversionistas no residentes, y de inversión extranjera directa (IED), mediante la adquisición de acciones en las instituciones financieras locales.

Para los fines del presente artículo, se define la globalización financiera como un proceso que supone la eliminación de la segmentación de los distintos mercados financieros locales, así como la interpenetración de los mercados monetarios y financieros nacionales y su integración con los mercados mundializados
(Chesnais, 1994). No son homogéneos los efectos de este proceso sobre los sistemas financieros nacionales, ya que dependen del grado de apertura financiera y de la gestión económica de los flujos de capital. Cuanto mayor sea el grado de apertura financiera - lo que se relaciona con la capacidad de los residentes de adquirir valores y asumir pasivos en moneda extranjera y el acceso de los no residentes a los diversos segmentos de los mercados financieros locales (Akyüz, 1992) - y mayor sea la receptividad de esa política a la entrada de recursos externos, más intensa será la influencia de esos flujos sobre los respectivos sistemas financieros.

Las características y los efectos sobre los mercados financieros de Argentina, México y Brasil de las corrientes de capitales provenientes del exterior se examinarán en la sección II, la expansión de la inversión extranjera directa en los sistemas financieros nacionales en la sección III y las conclusiones en la sección IV.

\section{II}

\section{Las corrientes de capitales externos}

En esta sección se presentarán las características generales del proceso reciente de apertura financiera de Argentina, México y Brasil. Se prestará especial atención al marco regulatorio que disciplina, por un lado, las colocaciones de los inversionistas no residentes y, por el otro, las transacciones monetarias y financieras en moneda extranjera - o denominadas en moneda extranjera- en los mercados financieros locales. El marco regulatorio influye sobre la composición de las inversiones extranjeras de cartera -inversiones en acciones o títulos de renta fija, públicos o privados, depósitos en moneda extranjera en bancos locales, o

Este artículo es una versión corregida y actualizada de un trabajo presentado a la 10a Conferencia Anual de la Society for the Advancement of Socio-Economics (Viena, 13 al 16 de julio de 1998). Las autoras agradecen los comentarios de un juez anónimo solicitados por la Revista de la CEPAL, y se responsabilizan por los errores y omisiones que puedan subsistir. colocaciones en fondos de inversión-y por ende en sus diversos efectos en los segmentos de los mercados financieros nacionales.

\section{El marco regulatorio}

La apertura financiera reciente de las economías latinoamericanas se inserta en un movimiento más general de transformación del mercado financiero internacional y forma parte integral de los programas de estabilización y reforma puestos en marcha a partir del segundo quinquenio de los años ochenta. Sin embargo, el grado de apertura financiera de los tres países es muy distinto. En la Argentina, la apertura financiera fue total, encontrándose México en un punto intermedio, mientras que en Brasil subsisten ciertas restricciones a la convertibilidad en la cuenta de capital y, principalmente, para las transacciones en moneda extranjera dentro del territorio nacional. 
La apertura financiera de la economía argentina en el decenio de 1990 fue un pilar central del programa de estabilización monetaria puesto en marcha por el gobierno de Carlos Menem. El plan de convertibilidad establecía un régimen de cambio fijo con convertibilidad monetaria, o sea, un régimen de currency board (Ferrari, 1998). En ese contexto, la estrategia adoptada para eliminar la hiperinflación y revertir el proceso de desmonetización se basó en la legalización del dólar. ${ }^{1}$ Esta estrategia implicó la total libertad de movimientos de capital entre el país y el exterior, ya que en ese tipo de régimen la base monetaria está determinada por la variación de las reservas internacionales, es decir, por el ingreso líquido de recursos externos.

Varias reformas institucionales hicieron posible y estimularon el desarrollo del segmento dolarizado de la economía argentina y su integración financiera con el exterior. En 1989 se obligó a las instituciones financieras a devolver los depósitos en la misma moneda en que habían sido efectuados y se negó al Banco Central el acceso a esos recursos. En 1991 se logró la liberalización total del mercado de cambio y se aprobó la Ley de Convertibilidad (Fanelli y Machinea, 1997). Además de establecer una paridad fija para el tipo de cambio y la convertibilidad del peso con relación al dólar, esta ley autorizó la denominación de contratos en cualquier moneda extranjera. La convertibilidad total de la cuenta de capital se consiguió después de lograr la desreglamentación del mercado de capitales en 1991 — con lo cual se eliminó el impuesto sobre las operaciones bursátiles y se autorizó a las empresas y a los bancos a emitir obligaciones negociables en moneda extranjera y valores comerciales (commercial papers) - y de aprobar la Ley de Amnistía Fiscal de 1992, que aceptaba, exenta de tributación, la repatriación de recursos de argentinos que estaban en el exterior (Blejer y Rozenwurcel, 1997). En 1992, con la nueva carta orgánica del Banco Central, se completó la reforma monetaria al establecerse la independencia del Banco Central de la República Argentina (BCRA), limitándose fuertemente su capacidad para financiar al gobierno y para actuar como prestamista de última instancia (Ferrari, 1998).

En México, el proceso reciente de apertura financiera incluyó la liberalización de las colocaciones de

\footnotetext{
1 En la Argentina se produjo una dolarización progresiva de las relaciones monetarias y financieras en el decenio de 1980, lo que representó una respuesta de los agentes ante la inflación crónica y, en una segunda etapa, ante la hiperinflación (Machinea, 1996).
}

los no residentes en los mercados accionario, de títulos públicos y monetario, y se insertó en el contexto más amplio de la reforma del sistema financiero nacional iniciada a fines del decenio de 1980 (Armella, 1993; Skiles, 1991).

La Ley Bursátil de diciembre de 1989 amplió las posibilidades de acceso de los inversionistas extranjeros al mercado de valores con la creación de una nueva modalidad de inversión, el Fondo Neutro, que permitió a estos inversionistas adquirir acciones de la serie A. ${ }^{2}$ Con este fondo, los inversionistas extranjeros pueden adquirir certificados de participación ordinaria (CPO) que incorporan los rendimientos de las acciones, pero no los derechos patrimoniales. Hasta entonces sólo existían dos tipos de inversión extranjera en el mercado accionario mexicano: los fondos país - carteras de acciones de las empresas más representativas de la bolsa mexicana cotizadas en los mercados financieros externos- y las acciones de libre suscripción (o serie B). Estas acciones, que constituyen el mecanismo tradicional de inversión extranjera en el mercado accionario mexicano, mantuvieron su primacía incluso después de la creación del Fondo Neutro (Caro Razú, 1994).

El elemento central de la liberalización de la cuenta de capital mexicana en los años noventa fue la apertura del mercado de títulos públicos. En 1990 se derogó la prohibición, vigente desde 1980, de su compra por inversionistas no residentes (Palomino, 1997, y Griffith-Jones, 1996). Además, en diciembre de 1991, en el ámbito de la desreglamentación del mercado monetario, se autorizaron las negociaciones de certificados de tesorería (Cetes), principal título negociado en ese mercado, entre los intermediarios financieros y los inversionistas extranjeros (Caro Razú, 1994). También se liberalizaron las colocaciones en títulos privados de renta fija.

Otras dos medidas ayudaron a estrechar los vínculos entre los capitales externos y el mercado financiero interno. Por un lado, se estableció un mecanismo simple y anónimo de repatriación de los recursos colocados en el exterior, que se gravan con una tasa única del 1\%. Por el otro, en noviembre de 1991, fue abolido el régimen de cambio dual, vigente desde 1982. Igual que en la Argentina, el incentivo para la repatriación del capital fue una medida fundamental, dada la intensidad de la fuga de capitales en el decenio de 1980 (Gurría, 1997).

\footnotetext{
${ }^{2}$ En México existen varios tipos de acciones: las de serie A garantizan el control del capital mientras que las demás (series B, C y L) sólo ofrecen dividendos sobre las acciones.
} 
El proceso de liberalización de la cuenta de capitales mexicana se acompañó con la liberalización parcial de las transacciones en moneda extranjera. De 1986 a 1991, los depósitos en moneda extranjera sólo estaban permitidos para las empresas localizadas en las cercanías de la frontera con los Estados Unidos. En 1991, esos depósitos fueron autorizados para las personas naturales domiciliadas en esas localidades y para las personas jurídicas mexicanas en general. Las condiciones de acceso de los no residentes a estos depósitos se hicieron más flexibles en 1993, pero siguieron limitadas. Sólo las representaciones oficiales de gobiernos extranjeros, los organismos internacionales y las personas naturales extranjeras que prestan servicios a estas instituciones pueden abrir cuentas en moneda extranjera en México. Por efecto de esas restricciones, estos depósitos captan un reducido volumen de recursos y se utilizan, fundamentalmente, en operaciones relacionadas con el comercio exterior (Banxico, 1997 y 1998). Sin embargo, en el contexto de la liberalización financiera interna, se autorizó la emisión de títulos denominados en moneda extranjera, como los Tesobonos - títulos del Tesoro de plazo muy corto (1 a 3 meses) indizados en dólar-y los certificados de depósito bancario denominados en dólares (Armella, 1993).

En el Brasil, con la apertura financiera del decenio de 1990 se liberalizaron significativamente las inversiones extranjeras de cartera en el mercado financiero nacional. Sin embargo, este movimiento fue menos intenso que en la Argentina y México, y alcanzó en forma heterogénea a los distintos mercados - monetario, de renta fija y accionario-. En el sistema bancario brasileño siguen prohibidos los depósitos y créditos en moneda extranjera de residentes y no residentes. Una de las principales condiciones que permitió cumplir esta disposición fue la creación de la moneda indizada en el decenio de 1980 (operaciones financieras de liquidez diaria), que al remplazar a la moneda nacional en sus funciones de reserva de valor y unidad de cuenta fue capaz de evitar la dolarización de las relaciones monetarias y financieras, como ocurrió en la Argentina. Sólo se permiten algunas transacciones denominadas en moneda extranjera, como los títulos públicos indizados al tipo de cambio y los créditos con corrección cambiaria. Sin embargo, la participación relativa de esos créditos en el sistema financiero brasileño no es aún significativa (Prates, 1997).

Se establecieron varias modalidades para la inversión extranjera de cartera, que se diferencian tanto en el tipo de instrumento utilizado —entrada directa o mediante fondos de inversión- cuanto en el segmento del mercado cambiario por el cual se efectúan. Hasta enero de 1998, el mercado de cambio oficial se componía de dos segmentos: el mercado de cambio comercial, en que se realizaban las transacciones comerciales y financieras estratégicas para la economía (balanza comercial, servicios de factores, deuda externa, inversión extranjera directa y las principales modalidades de la inversión extranjera de cartera), y el mercado de cambio fluctuante, en el cual se efectuaban las demás operaciones, como las transferencias unilaterales, el turismo, etc. (Souza, 1993).

En lo que toca al mercado de cambio comercial, en mayo de 1991 se autorizó la entrada directa y libre de restricciones de inversionistas institucionales extranjeros $^{3}$ en el mercado accionario interno. Sin embargo, el ingreso de personas naturales no residentes sigue vedado. Las demás alternativas de inversión se restringen a los fondos de inversión especializados, sujetos a criterios de colocación y tributación en el momento del ingreso al país y sobre las ganancias de capital, restricciones que no inciden sobre las inversiones en acciones. Entre esos fondos especializados, el más importante es el Fondo de Renta Fija de Capital Extranjero, cuyos recursos deben colocarse en papeles de renta fija, y un $40 \%$ como mínimo debe invertirse en títulos públicos. ${ }^{4}$

Los inversionistas extranjeros también tienen acceso al mercado financiero brasileño a través de las cuentas de no residentes del mercado de cambio fluctuante. Estas cuentas, constituidas en moneda nacional, no están sujetas a restricciones en cuanto al tipo de aplicación y constituyen el principal canal de ingreso de la afluencia de recursos especulativos (hot money). Como esas corrientes son atraídas por el diferencial entre los tipos de interés internos y externos, esa modalidad de inversión no resultaba rentable sino cuando dicho diferencial era importante, porque aparte del mayor riesgo cambiario que esas operaciones suponían - ya que debían efectuarse en el mercado de tasas fluctuantes - ellas eran penalizadas con una mayor tributación. Aparte aplicárseles el impuesto sobre las operaciones financieras a una tasa más ele-

\footnotetext{
${ }^{3}$ La legislación brasileña define en forma amplia a los inversionistas institucionales extranjeros. Como tal se consideran, aparte los fondos de pensiones y las compañías de seguros, las instituciones financieras extranjeras y los fondos de inversión constituidos en el exterior.

${ }^{4}$ Los demás fondos son: los fondos de privatización-capital extranjero, los fondos de inversión en empresas emergentes y los fondos de inversión inmobiliaria.
} 
vada, esas operaciones recibían el mismo tratamiento fiscal acordado a los residentes y estaban afectas incluso a la contribución provisoria sobre el movimiento financiero.

Con estos mecanismos, en virtud del marco regulatorio vigente se procuraba seleccionar los flujos de capital cursados en el mercado de cambio comercial, instituyendo modalidades de aplicación específicas para las inversiones de renta variable y de renta fija. Al mismo tiempo, se estableció un instrumento para el mercado de cambio fluctuante que tenía por objeto absorber los recursos externos más especulativos. ${ }^{5}$

\section{El impacto de las inversiones extranjeras de cartera sobre los mercados financieros latinoa- mericanos}

El impacto de las inversiones extranjeras de cartera sobre los mercados financieros latinoamericanos se diferencia en función de los distintos grados de apertura financiera, de las características específicas de cada sistema financiero y de las diferentes opciones de gestión macroeconómica de esas corrientes. Un aspecto fundamental es el de las modalidades de aplicación en los mercados financieros internos que fueron liberalizados. Las inversiones de cartera implican riesgos financieros considerables para los países periféricos, específicamente riesgos de crisis cambiaria y bancaria. Aún más, esos riesgos dependen tanto del plazo de las colocaciones como de sus características - inver-

\footnotetext{
${ }^{5}$ En febrero de 2000, el gobierno brasileño decidió acabar con las modalidades de aplicación específicas para las inversiones de renta variable y renta fija y autorizó inversiones de cartera de personas físicas en el mercado accionario brasileño. Estos cambios, que entrarán en vigor el 31 de marzo de 2000, amplían la apertura financiera de la economía brasileña, disminuyendo así las diferencias de grado de apertura entre los países analizados.
}

siones de renta fija o acciones, corrientes de plazo corto, mediano o largo (Comité de Basilea de Supervisión Bancaria, 1995).

En Argentina, el Banco Central no lleva un registro detallado de las corrientes de cartera dirigidas al mercado financiero interno, pero las inversiones de cartera corresponden, en general, a los movimientos de capital no especificados que se registran en la partida "otros movimientos" del balance de pagos (Fanelli y Machinea, 1997).

La recuperación de la demanda de activos financieros y del grado de monetización de la economía argentina se inició en 1991, después de adoptado el plan de convertibilidad, cuando cambiaron de dirección las corrientes de capital (cuadro 1). Tanto los residentes como los no residentes utilizaron los depósitos en dólares para internalizar recursos en el país. De esa forma, se protegían del riesgo de la desvalorización y aprovechaban los altos tipos de interés internos vigentes. La parte restante de las corrientes de capital se orientó a las bolsas de valores locales (Fanelli y Machinea, 1997).

El ingreso de capitales desempeñó un papel fundamental en la remonetización y en la recuperación del nivel de intermediación financiera (Blejer y Rozenwurcel, 1997). Sin embargo, la estabilización y la adopción de la convertibilidad monetaria no se tradujeron en una recuperación sustancial de la demanda de la moneda nacional, sino que, por el contrario, acentuaron la dolarización, ya que los depósitos en moneda extranjera llegaron a ser predominantes (Machinea, 1996).

La expansión del segmento dolarizado no evolucionó a parejas con el alargamiento de los plazos de los depósitos, que siguieron concentrados en los 30 días. Dado el mayor financiamiento en moneda extranjera, predominaban los créditos en dólares. La participación de esos créditos llegó al 58\% del total en 1994

CUADRO 1

Argentina: Los agregados monetarios de la economía, 1990-1997 (Porcentajes)

\begin{tabular}{|c|c|c|c|c|c|c|c|c|}
\hline & 1990 & 1991 & 1992 & 1993 & 1994 & 1995 & 1996 & 1997 \\
\hline $\mathrm{M}_{1}$ en $\%$ del PIB & 2.1 & 4.3 & 5.2 & 6.0 & 6.1 & 6.7 & 7.7 & 8.6 \\
\hline $\mathrm{M}_{2}$ en $\%$ del PIB & 3.8 & 7.4 & 9.5 & 11.8 & 11.9 & 11.1 & 13.0 & 11.1 \\
\hline $\mathrm{M}_{2}^{\mathrm{a}}$ en $\%$ del PIB & 5.0 & 11.1 & 14.4 & 19.0 & 20.0 & 19.5 & 23.1 & 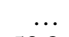 \\
\hline Depósitos (dólares/total) & 28.0 & 45.0 & 45.0 & 47.0 & 51.0 & 54.0 & 53.9 & 53.8 \\
\hline Depósitos a plazo (dólares/total) & 30.0 & 54.0 & 54.0 & 58.0 & 65.3 & 71.9 & 72.3 & $\ldots$ \\
\hline
\end{tabular}

Fuente: Datos del Banco Central de la República Argentina, en Fanelli y Machinea (1997); Carta económica, en Meyer (1997a); y Carta económica, en Ferrari (1998).

a Incluye los depósitos en dólares. 
frente al 40\% en 1991 (Ferrari, 1998). Esos recursos se canalizaron principalmente hacia las actividades productivas para el mercado interno y al financiamiento de bienes de consumo duraderos (Blejer y Rozenwurcel, 1997). De esta manera, la vulnerabilidad del sistema financiero argentino a la reversión de los flujos de capitales, inherente al régimen de convertibilidad, se agrava por la liquidez de los depósitos en dólares (y pesos) y por la concentración de los créditos en los sectores de no transables, que amplían la exposición de las carteras de los bancos a las desvalorizaciones cambiarias. La inexistencia de un prestamista de última instancia acentúa aún más esa vulnerabilidad, que se hizo evidente con la crisis de México de diciembre de 1994. La salida de capitales por el "efecto tequila" se tradujo en una grave crisis bancaria en el primer semestre de 1995 y en una profunda recesión económica.

Conviene señalar que la gestión macroeconómica subyacente al régimen de convertibilidad interna supone un grado significativo de receptividad a los flujos de capital. En ese régimen, la entrada de capitales no influye en las políticas cambiaria y monetaria $-\mathrm{y}$ no se traduce, por lo tanto, en un aumento de la deuda pública-, sino en la expansión de los depósitos en dólares en los bancos, lo que a su vez estimula la demanda y la actividad económica internas.

En México, las inversiones extranjeras de cartera representaban más del $60 \%$ de los flujos de capital absorbidos por el país en el período 1990-1994. Esos flujos se orientaron, esencialmente, hacia la compra de acciones y documentos del gobierno mexicano (cuadro 2). Las colocaciones en el sistema bancario, como los depósitos a plazo y los certificados bancarios denominados en moneda extranjera, no fueron importantes. El segmento del mercado financiero mexicano más afectado por la apertura financiera fue el mercado de títulos públicos. Con relación al mercado accionario, el impacto de las inversiones extranjeras de cartera fue menos significativo, ya que, hasta 1995, la mayor parte de las acciones fueron adquiridas usando los títulos de depósito en el mercado estadounidense, American Depository Receipts (ADR). Hubo así un traslado de liquidez hacia las bolsas de valores estadounidenses, principalmente a la Bolsa de Nueva York. En México y Argentina la huida de las bolsas de valores locales se vio estimulada por la utilización de los programas de ADR en el proceso de privatización. Esos programas tenían por objeto reducir la posibilidad de saturación del mercado local, dado el volumen de las acciones transadas en relación con el tamaño de esas bolsas (CEPAL, 1995).

El gran volumen de colocaciones de los inversionistas extranjeros en títulos públicos hasta que estalló la crisis mexicana a fines de 1994 fue la característica principal de México, en comparación con los otros países analizados. En el período 1990-1994 esas operaciones representaban un 55\% del total de las inversiones extranjeras de cartera. Entre 1991 y 1993, los no residentes absorbieron la mayor parte de las nuevas emisiones de títulos públicos, sobre todo de corto plazo. Su participación en el total de la deuda pública mexicana subió de $8 \%$ a fines de 1990 a $57 \%$ a fines de 1993 (Griffith-Jones, 1996).

En 1994 se produjo un cambio significativo en la composición de la deuda pública en manos de los

CUADRO 2

México: Las inversiones extranjeras de cartera en el mercado financiero del país, 1991-1997 (Millones de dólares)

\begin{tabular}{|c|c|c|c|c|c|c|c|c|c|c|c|c|}
\hline \multirow[t]{3}{*}{ Años } & \multicolumn{5}{|c|}{ Acciones } & \multicolumn{6}{|c|}{ Obligaciones del gobierno } & \multirow[t]{3}{*}{ Total } \\
\hline & \multicolumn{2}{|c|}{ Mercados de ADR } & \multicolumn{2}{|c|}{$\begin{array}{c}\text { Mercado bursátil } \\
\text { mexicano }^{\mathrm{a}}\end{array}$} & \multirow[t]{2}{*}{ Total } & \multicolumn{2}{|c|}{ Cetes } & \multicolumn{2}{|c|}{ Tesobonos } & \multicolumn{2}{|c|}{ Otros } & \\
\hline & Existencia & $\%$ total & Existencia & $\%$ total & & Existencia & $\%$ total & Existencia & $\%$ total & Existencia & $\%$ total & \\
\hline 1991 & 13.7 & 73.9 & 4.9 & 26.1 & 18.6 & 3.0 & 54.0 & 0.3 & 4.7 & 2.2 & 41.3 & 5.5 \\
\hline 1992 & 21.2 & 73.8 & 7.5 & 26.2 & 28.7 & 9.2 & 64.3 & 0.2 & 1.4 & 4.8 & 34.3 & 14.2 \\
\hline 1993 & 34.0 & 62.2 & 20.6 & 37.8 & 54.6 & 15.4 & 70.2 & 1.3 & 5.9 & 5.2 & 23.9 & 21.9 \\
\hline 1994 & 21.2 & 61.6 & 13.2 & 38.4 & 34.4 & 2.5 & 12.3 & 17.4 & 85.0 & 0.6 & 2.7 & 20.5 \\
\hline 1995 & 15.2 & 62.1 & 9.3 & 37.9 & 24.5 & 2.8 & 82.0 & 0.2 & 5.6 & 0.4 & 12.4 & 3.4 \\
\hline 1996 & 15.1 & 48.8 & 15.9 & 51.2 & 31.0 & 3.0 & 89.2 & - & - & 0.4 & 10.8 & 3.4 \\
\hline 1997 & 23.1 & 47.2 & 25.7 & 52.5 & 48.8 & 3.0 & 90.3 & - & - & 0.3 & 90.7 & 3.3 \\
\hline
\end{tabular}

Fuente: Banxico, 1998.

a Incluye las acciones de libre suscripción, Fondo Neutro y los fondos del país. 
inversionistas extranjeros. Los Cetes - títulos denominados en pesos - fueron sustituidos progresivamente por los Tesobonos, títulos de cortísimo plazo indizados en dólares (cuadro 2). Después de febrero de ese año, por el alza de la tasa de interés estadounidense y del riesgo cambiario - asociado con la trayectoria ascendente del déficit en cuenta corriente- la prima exigida por los inversionistas extranjeros para mantener sus posiciones en Cetes subió considerablemente. Para evitar la elevación desmesurada del costo de la renovación (roll-over) de la deuda pública y la salida de capitales, el gobierno empezó a ofrecer los Tesobonos a los inversionistas no residentes. En consecuencia, a mediados de 1994 esos inversionistas tenían el 80\% de las existencias de tales títulos fuera del sistema bancario (Goldestein y Turner, 1996).

La experiencia mexicana muestra los efectos negativos que puede tener la apertura del mercado de títulos de la deuda pública a los inversionistas extranjeros, principalmente cuando estos títulos son de corto plazo y denominados en moneda extranjera. El mercado de Tesobonos fue uno de los principales focos de la crisis cambiaria de $1994 .{ }^{6} \mathrm{El}$ volumen de esos títulos en poder de no residentes, que superaba el de las reservas internacionales, aumentó la vulnerabilidad del balance de pagos y de las cuentas públicas ante la posible reorientación de las corrientes de capitales. Frente a la creciente desconfianza con relación a la capacidad del gobierno mexicano de cumplir con el pago de esos títulos, los inversionistas extranjeros procedieron a vender sus posiciones. Como era reducido el nivel de las reservas frente a la dimensión de la fuga de capitales, el Banco Central no logró contener la crisis cambiaria y debió optar por la fluctuación del tipo de cambio. Además, el sector público se enfrentó a la necesidad de refinanciar un elevado monto de deudas de corto plazo denominadas en dólares, cuyo valor en moneda nacional había subido por efecto de la desvalorización cambiaria.

Cabe señalar que gran parte del aumento de la deuda pública se asoció con la política monetaria de esterilización parcial del ingreso de recursos externos. Al evitar la caída de la tasa de interés interna, esa política estimulaba las corrientes de capitales. Sin embargo, como la deuda pública era adquirida por no residentes, la política de esterilización no reducía la vul-

\footnotetext{
${ }^{6} \mathrm{El}$ segundo foco fue el sistema bancario, pues los bancos tenían existencias elevadas de pasivos en moneda extranjera de corto plazo, y una parte de esos pasivos tenía Tesobonos de garantía. Sobre la crisis bancaria mexicana véase Griffith-Jones (1996) y FolkertsLandau, Mathieson y Schinasi (1997).
}

nerabilidad de la economía y del sistema financiero a los flujos de capital. Por el contrario, esa estrategia acentuó la fragilidad externa de la economía mexicana. Aparte la política de esterilización, la flexibilización de la política cambiaria, con la adopción de bandas cambiarias en 1991 y los superávit fiscales contribuyeron a neutralizar en parte el impacto monetario de los recursos externos (Gurría, 1997).

En el Brasil, la casi totalidad de los inversionistas extranjeros de cartera actuaron en la bolsa de valores de São Paulo (Bovespa), la principal del país. La captación de recursos externos mediante fondos de inversión no fue significativa. Sólo el Fondo de Renta Fija de Capital Extranjero (FRFCE) captó un volumen algo importante de recursos en los momentos de más alta diferencia de tasas de interés, principalmente en títulos de deuda pública indizados según el tipo de cambio, parecidos a los Tesobonos mexicanos. Las inversiones en las cuentas de no residentes también se canalizaron predominantemente hacia esos títulos. Sin embargo, sigue siendo pequeño el volumen en poder de no residentes.

Siendo así, los efectos de la apertura financiera se concentraron en el mercado secundario de acciones. Al contrario de lo que ocurrió en México, hasta 1997 el número de programas ADR de las empresas brasileñas era pequeño en términos absolutos y en comparación con los demás países latinoamericanos y el valor de mercado de las acciones negociadas en el mercado de ADR correspondía apenas a $6.5 \%$ de la capitalización de la Bovespa en diciembre de 1997 (Freitas y Prates, 1999). Esta particularidad puede explicarse por la dimensión del mercado brasileño, que tiene una mayor capitalización y por consiguiente mayor liquidez que el mercado mexicano. Además, en el Brasil el proceso de privatización no ha supuesto, hasta ahora, la emisión de ADR. La participación de los inversionistas extranjeros en el total negociado en la Bovespa aumentó significativamente en los últimos tiempos, de $6.5 \%$ en 1991 a $29.4 \%$ en 1995. Junto con el crecimiento de esa participación se produjo la ampliación continua de los volúmenes transados y de la capitalización del mercado (cuadro 3$)^{7}$

En cambio, la apertura financiera no ayudó a reducir el grado de concentración del mercado secundario ni a dinamizar el mercado primario de acciones. Las

\footnotetext{
${ }^{7}$ Cabe mencionar que el aumento de más de $100 \%$ en el volumen transado entre 1996 y 1997 obedece a las privatizaciones de Vale do Rio Doce y de varias empresas de energía eléctrica estatales. También estimuló estos movimientos el avance del proceso de privatización de los sistemas Telebras y Eletrobras.
} 
CUADRO 3

Brasil: Participación de los inversionistas extranjeros

en la bolsa de valores de São Paulo, 1991-1997

\begin{tabular}{ccccc}
\hline Años & Inversión extranjera $^{\mathrm{a}}$ & Volumen total negociado $^{\mathrm{b}}$ & Capitalización del mercado $^{\mathrm{b}}$ & Principal acción negociada $^{\mathrm{c}}$ \\
\hline 1991 & 6.0 & 28.4 & 43615.1 & 41.3 \\
1993 & 16.0 & 96.4 & 99430.1 & 50.2 \\
1994 & 21.4 & 303.6 & 189058.2 & 40.1 \\
1995 & 29.4 & 233.3 & 147560.0 & 49.8 \\
1996 & 28.6 & 356.0 & 216927.0 & 61.2 \\
1997 & 25.9 & 786.7 & 255409.0 & 55.86 \\
\hline
\end{tabular}

Fuente: BOVESPA (varios números).

a Participación extranjera en el volumen total negociado, en porcentajes.

b En millones de dólares.

c En porcentaje del volumen total negociado.

colocaciones de los inversionistas extranjeros se concentraron en las acciones de las empresas estatales en vías de privatización, sobre todo Telebras (Telecomunicaciones Brasileñas), ante la perspectiva de su valorización una vez privatizadas. Por este motivo, el valor de mercado y la liquidez de las acciones de empresas privadas siguieron en niveles reducidos, lo que desalentó la demanda de los inversionistas y las nuevas emisiones. El volumen poco importante de las emisiones primarias implicó una menor participación relativa de las acciones de esas empresas en el mercado secundario, aumentando así la concentración de las transacciones en los valores más líquidos (Prates, 1999).

Aunque las inversiones de cartera en acciones son menos volátiles que las colocaciones de renta fija, debido al mayor riesgo de pérdida de capital, esas inversiones también implican riesgos financieros para los países periféricos. Por el gran volumen de las corrientes de capital frente al tamaño de los mercados accionarios, los movimientos de reacomodo de las carteras de los inversionistas extranjeros tienen un fuerte impacto sobre el precio de las acciones (Akyüz, 1992). Fueron evidentes los efectos de esos movimientos sobre el mercado accionario brasileño durante las crisis mexicana y asiática. En esas dos ocasiones - primer trimestre de 1996 y último trimestre de 1997- las cotizaciones registraron fuertes desvalorizaciones debido a la venta de posiciones por parte de inversionistas extranjeros para cubrir sus pérdidas en otros mercados emergentes o para aumentar su encaje destinado a hacer frente a los rescates de sus cotizantes.

\section{III}

\section{El crecimiento de las inversiones extranjeras directas en los sistemas financieros nacionales}

Los mercados financieros de los países latinoamericanos atrajeron también, durante el decenio de 1990, inversión extranjera directa en la forma de participación accionaria en empresas de intermediación financiera local y en la instalación de nuevas sucursales o subsidiarias controladas íntegramente por instituciones financieras extranjeras. Por un lado, esa tendencia se vio estimulada por la nueva dinámica competitiva de las instituciones financieras de los países industrializados, caracterizada por la eliminación de las barreras entre las actividades de los bancos y de las instituciones financieras no bancarias y por la concentración y centralización de los capitales en los mercados nacionales en la forma de fusiones y adquisiciones. Por otro lado, también se facilitó el proceso por la abolición o flexibilización de las restricciones existentes en varios países y el establecimiento de filiales o sucursales de instituciones extranjeras en el mercado nacional, la 
participación de no residentes en el capital social de las instituciones nacionales y las actividades de los intermediarios financieros extranjeros en los mercados locales. Esas medidas de liberalización del trato conferido a las instituciones financieras extranjeras fueron adoptadas tanto por los países industrializados como por los países periféricos (Freitas, 1999).

La intensificación de las presiones de la competencia en los mercados nacionales de los países centrales estimuló a los bancos y a otros intermediarios financieros a buscar nuevos campos de valorización. En un afán de afianzar su posición global, las instituciones financieras optaron por la diversificación geográfica de sus actividades con el establecimiento de sucursales o subsidiarias en países extranjeros. La principal diferencia entre esa evolución y la internacionalización de los años sesenta y setenta radica en el hecho de que las estrategias de apoyo a las empresas transnacionales y de financiamiento externo dominantes en aquel entonces cedieron su lugar a la estrategia de diversificación de las actividades en los mercados locales de los países anfitriones. Este proceso exige redes más densas y una mayor integración de las instituciones extranjeras en el sistema bancario local.

Junto con la necesidad de diversificación fuera de los mercados nacionales saturados, la estabilidad de las economías latinoamericanas, las perspectivas de numerosos negocios rentables y el predominio de los competidores locales relativamente más débiles estimularon la entrada reciente de importantes grupos financieros a la región. Los países de habla hispana fueron los primeros blancos de las inversiones directas de esos grupos. En la segunda mitad de los años ochenta, le sonó la hora al Brasil. El mercado brasileño llegó a ser el más cotizado de la región, ya que ofrecía una fuente de importantes utilidades para los bancos extranjeros allí instalados.

En la presente sección se examinará la expansión reciente de las instituciones bancarias en Argentina, Brasil y México. Para comenzar se analizarán las modificaciones en el tratamiento legal y regulatorio que se dio al capital extranjero. En seguida, se examinarán las estrategias de expansión adoptadas por los bancos extranjeros en esos tres países, así como los resultados de su gestión.

\section{La modificación del tratamiento legal conferi- do al capital extranjero}

Los tres países analizados presentan características distintas en lo que se refiere al tratamiento legal otor- gado a las instituciones extranjeras. Mientras que en la Argentina esas instituciones encontraron un ambiente regulatorio más favorable, en México y en el Brasil las condiciones vigentes para el establecimiento de filiales por instituciones no residentes y para la participación en el capital social de las instituciones nacionales locales eran más restrictivas. Por ello se observan distintos grados de apertura y de liberalización.

En la Argentina, la apertura del sistema financiero local fue promovida en el contexto de la reforma financiera de 1977. En esa oportunidad, se abolieron todas las restricciones a la entrada de nuevas instituciones y a la expansión de las redes bancarias, fuera por las instituciones nacionales o por las extranjeras (Feldman y Sommer, 1984). En la práctica, la legislación argentina adoptó el principio del trato nacional para los bancos extranjeros, por el cual se aplican a esas instituciones las mismas reglas, o reglas no menos favorables, que las que se aplican a las instituciones nacionales. Además esa legislación amplió el conjunto de actividades permitidas a todos los bancos.

El tratamiento no discriminatorio otorgado al capital extranjero permitió recientemente la desnacionalización del sistema financiero argentino. Las instituciones extranjeras que durante el período de alta inflación ocupaban posiciones modestas en el mercado local iniciaron a partir de 1997 una serie de adquisiciones (y compras de participación) de los bancos nacionales. Actualmente, con excepción de los dos grandes bancos públicos - el Banco de la Nación y el Banco de la Provincia de Buenos Aires-y un banco privado (Banco Galicia y Buenos Aires), los principales bancos argentinos están bajo el control de no residentes.

Los tres mayores bancos privados bajo control de no residentes han ampliado continuamente sus cuotas de mercado, con la introducción de nuevos productos (Folkerts-Landau, Mathieson y Schinasi, 1997, p. 161). La concentración del sistema bancario argentino también se refleja en el número de instituciones, que bajó de 205 en diciembre de 1994 a 138 en diciembre de 1997.

En México, hasta el decenio de 1990 se prohibía la entrada de bancos extranjeros. La presencia de esas instituciones era permitida sólo como oficina de representación, con un campo de actividad muy limitado, ya que no podían efectuar operación alguna de intermediación financiera. Además, desde la estatización del sistema bancario en 1981 hasta la privatización de comienzos de los años noventa, se prohibió la creación de nuevas instituciones bancarias incluso por los residentes. 
En julio de 1990, con la promulgación de una nueva ley de instituciones crediticias, se inició la flexibilización de las condiciones de acceso de las instituciones financieras extranjeras al sistema financiero local. En virtud de esa ley, la Secretaría de Hacienda y Crédito Público, responsable de la reglamentación de las instituciones financieras, fue investida de poderes para autorizar el establecimiento en el país de agencias de bancos extranjeros. Sin embargo, esas sucursales sólo podían operar con no residentes (Ferreira y otros, 1998). En esa misma oportunidad se autorizó la participación extranjera minoritaria en el capital social de las empresas de corredores.

En abril de 1994, en el ámbito del Tratado de Libre Comercio de América del Norte, se aprobaron las reglas para el establecimiento de filiales mexicanas de las instituciones financieras extranjeras. De ese modo, se autorizó la apertura directa de filiales de los bancos y de los corredores de bolsa estadounidenses y canadienses, así como la constitución de diez grupos financieros extranjeros, de los cuales seis estaban integrados por un banco. Además, trece filiales de compañías de seguros extranjeras fueron autorizadas para operar en el país (Palomino, 1997).

Un nuevo relajamiento de las restricciones a los bancos extranjeros en México ocurrió en el contexto de la grave crisis del sistema bancario de 1994. Con el objetivo de fortalecer el capital de las instituciones trizadas por la crisis, la legislación relativa a la estructura del capital social de los bancos y de las sociedades de control de los grupos financieros fue reformada en febrero de 1995 para permitir la participación de personas jurídicas extranjeras (Banxico, 1996). Se autorizó a los no residentes a adquirir acciones de la serie B y L, dentro del límite individual del $20 \%$ del capital de las instituciones mexicanas. Sin embargo, ese límite podía ampliarse en el caso de que la filial de un banco extranjero adquiriera el control de un banco nacional al suscribir la totalidad de las acciones de la serie A. Para evitar que los bancos más grandes fueran adquiridos por instituciones extranjeras, la Secretaría de Hacienda y Crédito Público dispuso que un banco extranjero individual no podía poseer más de un $6 \%$ de los activos totales del sistema bancario interno (Meyer, 1997b).

Conviene señalar que el gobierno mexicano autorizó la participación de instituciones extranjeras en el proceso de privatización bancaria. Sin embargo, esa participación se limitaba a un 30\% del capital total, con un tope máximo individual de 5\% para cada inversionista. A fines de 1998, el Congreso mexicano eliminó esa restricción, con lo cual tornó posible el control mayoritario extranjero de los bancos comerciales nacionales, incluso de los tres más grandes: Banamex, Bancomer y Serfin (Taylor, 1999).

En el Brasil, con excepción del período 1946 a 1964, cuando rigió una libertad completa de acceso de las instituciones extranjeras al sistema financiero nacional, siempre hubo reglas restrictivas, ya sea para el ingreso de los bancos extranjeros o en sus condiciones operacionales en el mercado local. Desde la reforma financiera de 1965 hasta 1995, las inversiones extranjeras directas en el sistema bancario, así como el conjunto de actividades permitidas a los bancos extranjeros, dependían de la aplicación del principio de reciprocidad. Con este criterio, el gobierno brasileño autorizaba exclusivamente la entrada de bancos originarios de los países que permitían el acceso de los bancos brasileños a sus sistemas financieros. Sin embargo, el establecimiento de oficinas de representación estuvo permitido libremente en todo ese período.

A partir de la promulgación de la Constitución de 1988, el acceso del capital extranjero al sistema financiero quedó virtualmente prohibido, ya que dependía de la elaboración por el Congreso de un marco reglamentario cuya ley normativa todavía no ha sido promulgada. Sin embargo, el artículo 52 de las Disposiciones Constitucionales Transitorias dejó abierta la posibilidad del ingreso de instituciones extranjeras al mercado brasileño, previendo autorizaciones resultantes de acuerdos internacionales al amparo del principio de reciprocidad, en contrapartida por el establecimiento de filiales de bancos brasileños en el exterior y de circunstancias consideradas de "interés nacional" por el gobierno. Las solicitudes serían examinadas caso por caso, con la aprobación final del Presidente de la República.

En agosto de 1995, aprovechando esta prerrogativa, el gobierno estableció, a través de la Exposición de Motivos $\mathrm{N}^{\circ} 311$, que era de interés para el país permitir la entrada o la ampliación de la participación extranjera en el sistema financiero nacional. Esa decisión se tomó en el contexto de la fragilidad creciente del sistema financiero nacional, afectado por una brutal contracción de la liquidez a consecuencia de las medidas económicas restrictivas adoptadas para hacer frente al impacto de la crisis mexicana. Igualmente, la apertura del sistema financiero satisfacía el interés de numerosas instituciones financieras extranjeras y cedía parcialmente a las exigencias internacionales expresadas en numerosos foros, como la Organización Mundial del Comercio, el Mercosur y el Área de Libre Comercio de las Américas. 
La apertura del mercado de capitales, el proceso de privatización y de reestructuración industrial, y los negocios asociados con el financiamiento de la renovación de la infraestructura económica fueron los principales atractivos para la inversión extranjera directa en el sistema financiero brasileño. Diversas instituciones financieras manifestaron gran interés en operar en el país, para aprovechar las grandes posibilidades de negocio y lucro que existían, sobre todo en el sector bancario de inversiones. El potencial de crecimiento del mercado minorista y de cuentas bancarias también ejerce una fuerte atracción para los bancos extranjeros, tanto los recién llegados como los que ya están instalados en el país. Mientras que en el Brasil existe una agencia bancaria por cada 4500 personas, en Alemania hay una por cada 2000 y en España, una por cada 1100 (The Economist, 1998, p. 61).

El anuncio de la decisión gubernamental de autorizar la participación extranjera en el capital social de las instituciones privadas nacionales y en la privatización de los bancos públicos, así como el establecimiento de nuevas subsidiarias extranjeras, estimuló el interés de las instituciones extranjeras en ingresar al mercado financiero local. Desde agosto de 1995 se multiplicaron los contactos entre los bancos locales y los extranjeros interesados en asociarse con ellos, adquiriendo una participación mayoritaria o incluso integral.

Ese movimiento asumió tales proporciones que el Banco Central comenzó a exigir a quienes solicitaban autorización de ingreso o de ampliación de actividades el pago de una especie de "peaje" a título de contribución por los recursos públicos utilizados en el saneamiento del sistema financiero, salvo en los casos en que las instituciones financieras adquirieran bancos en bancarrota o con graves problemas financieros (Freitas, 1999).

Esas iniciativas de flexibilización de las condiciones de ingreso o de funcionamiento de los bancos extranjeros han sido muy recomendadas a los gobiernos de los países en desarrollo por los representantes de organismos multilaterales como el Fondo Monetario Internacional o el Banco Mundial. Según el criterio de estos organismos oficiales, la mayor participación del capital extranjero en los sistemas bancarios locales ayudará a fortalecer la capacidad de estos sistemas para capear las crisis macroeconómicas, ya que las dificultades de las subsidiarias locales de los bancos extranjeros no se traducirán en la bancarrota. Además, por la introducción de una "mayor competencia" se espera que el capital financiero extranjero resuelva las principales insuficiencias de los mercados financieros locales, como, por ejemplo, los márgenes y costos muy altos en comparación con los internacionales, la elevada concentración de los riesgos y la existencia de mercados restringidos.

\section{Las estrategias de expansión de los bancos extranjeros}

Con el propósito de diversificar sus actividades en el extranjero, los bancos adoptan diversas estrategias de expansión, adaptándose al marco regulatorio y legal del país anfitrión. Para los recién llegados la opción está entre instalar una sucursal o una subsidiaria local con control integral o adquirir una participación accionaria en una institución nacional. Los bancos extranjeros ya instalados suelen preferir o el crecimiento gradual mediante el establecimiento de una red de agencias para la expansión de su base de negocios o una política agresiva de compra de cuotas del mercado por la absorción de sus competidores. La forma de expansión guarda estrecha relación con la gama de instituciones en los diferentes mercados. Esta tipología puede aplicarse en el análisis de la expansión reciente de la actividad de las instituciones bancarias extranjeras en América Latina.

Como muestra el cuadro 4, en México los bancos extranjeros aprovecharon las medidas de flexibilización de las condiciones de acceso después de la crisis financiera de 1995 para adquirir participaciones de capital en las instituciones locales puestas bajo el control del organismo supervisor, la Comisión Nacional Bancaria y de Valores, y/o financiadas por el Fobaproa, el fondo de garantía de los depósitos bancarios. En el Brasil, algunas instituciones extranjeras optaron también por adquirir el control accionario de los bancos locales, mientras otras se inclinaron por la creación de sucursales o subsidiarias.

En lo que se refiere a la expansión de los bancos ya establecidos en la región, el examen de la evolución reciente muestra que en la Argentina el medio preferido de las instituciones extranjeras para reforzar sus posiciones en el mercado local fue la absorción o adquisición de participación mayoritaria en los bancos locales (cuadro 5). En el Brasil, los bancos más antiguos del país, como el Lloyds Bank y el ABN-Amro Bank, adoptaron estrategias de expansión distintas. En México, en agosto de 1997, la subsidiaria del Citibank, única sobreviviente de la estatización del decenio de 1980, adquirió el banco Confia. Ese banco había sufrido la intervención del Banco Central debido a sus 
CUADRO 4

Brasil y México: Los principales participantes en la internacionalización bancaria, 1995-1998

\begin{tabular}{|c|c|c|c|}
\hline Anfitrión & Institución & País de origen & Forma de entrada \\
\hline \multirow[t]{6}{*}{ Brasil } & $\begin{array}{l}\text { Hong Kong Shanghai Banking } \\
\text { Corporation (HSBC) }\end{array}$ & Reino Unido & $\begin{array}{l}\text { Adquisición de los activos del Banco Bamerindus, en situación de } \\
\text { falencia }\end{array}$ \\
\hline & Groupe Crédit Suisse & Suiza & Adquisición del Banco Garantía \\
\hline & Nations Bank & Estados Unidos & Adquisición de $51 \%$ del capital del Banco Liberal \\
\hline & United Bank of Switzerland & Suiza & Establecimiento de subsidiaria de control integral \\
\hline & Banco Bilbao Vizcaya (BBV) & España & Adquisición del Banco Excel-Económico, en situación de falencia \\
\hline & Rabobank & Países Bajos & Establecimiento de sucursal \\
\hline \multirow[t]{7}{*}{ México } & Banco Bilbao Vizcaya (BBV) & España & Adquisición del $70 \%$ del grupo Probusa \\
\hline & Bank of Nova Scotia & Canadá & Adquisición del $45 \%$ de capital del banco Inverlat \\
\hline & Bank of Montreal & Canadá & Adquisición del $16 \%$ de Bancomer \\
\hline & A.G. Alemania & Alemania & Adquisición del control del banco Banoro y Bancrecer \\
\hline & Banco Santander & España & $\begin{array}{l}\text { Establecimiento de subsidiarias y adquisición de } 51 \% \text { del capital de } \\
\text { Banco Mexicano }\end{array}$ \\
\hline & $\begin{array}{l}\text { Hong Kong Shanghai Banking } \\
\text { Corporation }\end{array}$ & Reino Unido & Adquisición de $20 \%$ del capital del grupo Serfin \\
\hline & Banco Central Hispanoamericano & España & Adquisición de $10 \%$ del capital del grupo Prima International \\
\hline
\end{tabular}

Fuente: Conger (1998), Freitas (1999), Warner (1995 y 1998), Del Villar y otros (1997), Taylor (1997a y b), The Banker (1997a ), Cypher (1996).

CUADRO 5

América Latina: Ejemplo de expansión reciente de bancos extranjeros

\begin{tabular}{|c|c|c|c|}
\hline Anfitrión & Institución & País de origen & Formas de expansión \\
\hline \multirow[t]{8}{*}{ Argentina } & $\begin{array}{l}\text { Hong Kong Shanghai Banking } \\
\text { Corporation (HSBC) }\end{array}$ & Reino Unido & Adquisición del $100 \%$ del Banco Roberts \\
\hline & BankBoston & Estados Unidos & Aumento de la red de agencias \\
\hline & Banco Santander & España & Adquisición del $51 \%$ del capital social del Banco Río de la Plata \\
\hline & Bank of Nova Scotia & Canadá & $\begin{array}{l}\text { Aumento de la participación accionaria de } 25 \% \text { a } 100 \% \text { en el } \\
\text { capital del Banco Quilmes }\end{array}$ \\
\hline & Grupo Socimer & Suiza & Adquisición del $30 \%$ del capital del Banco Patricios \\
\hline & Bankers Trust & Estados Unidos & Adquisición del 51\% del Banco Liniers Sudamericano \\
\hline & Crédit Agricole & Francia & Adquisición de 1/3 del capital del Banco Bisel \\
\hline & Banco Bilbao Vizcaya (BBV) & España & $\begin{array}{l}\text { Fusión del Banco Francés del Río de la Plata, controlado por el } \\
\text { BBV, con el Banco de Crédito Argentino }\end{array}$ \\
\hline \multirow[t]{7}{*}{ Brasil } & Citibank & Estados Unidos & Ampliación de la red de agencias \\
\hline & BankBoston & Estados Unidos & Ampliación de la red de agencias \\
\hline & Banco Santander & España & $\begin{array}{l}\text { Adquisición del } 51 \% \text { del capital del Banco Geral do Comércio y } \\
\text { del Banco Noroeste }\end{array}$ \\
\hline & Lloyds Bank & Reino Unido & Adquisición del Banco Multiplic y de su financiera \\
\hline & ABN-Amro Bank & Países Bajos & Adquisición del $40 \%$ del capital del Banco Real \\
\hline & Chase Manhattan & Estados Unidos & Adquisición del Banco Patrimônio \\
\hline & Banque Nationale de Paris (BNP) & Francia & Adquisición del Banco FonteCindam \\
\hline México & Citibank & Estados Unidos & Adquisición del Banco Confia \\
\hline
\end{tabular}

Fuente: Conger (1998), Freitas (1999), Warner (1995 y 1998), Taylor (1997a y b), The Banker (1997a y b).

actividades irregulares en el extranjero (The Banker, 1997b, p. 46).

En los tres países analizados, las estrategias agresivas adoptadas por los bancos españoles y también por nuevos rivales como el Hong Kong Shanghai Banking Corporation (HSBC) obligaban a los bancos extranjeros establecidos desde hacía mucho tiempo en la región a tomar medidas defensivas. Algunos optaron por am- 
pliar sus redes de agencias, como el BankBoston en Brasil y la Argentina, mientras que otros decidieron comprar bancos locales o adquirir participaciones accionarias, como el Bankers Trust en Argentina, y el Lloyds Bank, el Chase Manhattan y el ABN-Amro en el Brasil.

El resultado de ese movimiento reciente de internacionalización sugiere una tendencia a que las instituciones extranjeras adquieren importancia creciente en los mercados financieros locales de los países analizados. Sin embargo, el ritmo de ampliación de la presencia extranjera varía considerablemente de uno a otro país. Entre diciembre de 1994 y diciembre de 1998 la participación extranjera en los sistemas financieros locales aumentó más rápidamente en México que en Brasil y Argentina (cuadro 6). En México, esa expansión fue importante: los bancos extranjeros poseían al final de 1998 un $40 \%$ del mercado frente al $1.2 \%$ en 1994. En el Brasil, el avance de los bancos extranjeros fue también considerable, en particular en los años 1997 y 1998. En la Argentina, el último dato disponible es de 1997. No obstante, es posible inferir que la participación extranjera ha subido en 1998 porque ha continuado el proceso de adquisición de bancos nacionales.

La diferente intensidad del proceso de internacionalización refleja la heterogeneidad de los marcos regulatorios vigentes en cada país. El sistema bancario argentino, por ser el más abierto, presenta la mayor probabilidad de que avance la participación extranjera. En México todavía están en vigor algunas restricciones legales que limitan las posibilidades de expan-

\begin{tabular}{lccc} 
CUADRO 6 & $\begin{array}{l}\text { Argentina, Brasil y México: Evolución de la } \\
\text { participación extranjera en los sistemas } \\
\text { financieros nacionales }\end{array}$ \\
\hline País & \multicolumn{3}{c}{ Activos en \% de los activos totales } \\
& \multicolumn{3}{c}{ del sistema bancario } \\
\cline { 2 - 4 } & $\begin{array}{r}\text { Diciembre } \\
\text { de } 1994\end{array}$ & $\begin{array}{c}\text { Diciembre } \\
\text { de } 1997\end{array}$ & $\begin{array}{c}\text { Diciembre } \\
\text { de } 1998\end{array}$ \\
\hline Argentina & 21.7 & 45.0 & $\ldots$ \\
Brasil & 11.0 & 21.1 & 22.5 \\
México & 1.2 & 19.9 & 40.0 \\
\hline
\end{tabular}

Fuente: Goldenstein y Turner (1996), Palomino (1997), FolkertsLandau, Mathieson y Schinasi (1997, p. 165), The Economist (1997), KPMG Peat Marwick (1998) y Conger (1999). sión de las instituciones financieras, a despecho de la nueva ley financiera aprobada por el Congreso a fines de 1998. El Brasil se encuentra en una situación intermedia, ya que el resquicio legal abierto por el gobierno puede cerrarse si el Congreso decide finalmente promulgar una ley para el sistema financiero, que, cediendo a la presión de los influyentes banqueros nacionales, restaure las limitaciones anteriormente en vigor.

Las diferencias en los aspectos institucionales de las finanzas en esos tres países ciertamente explican también el mayor o menor éxito que han tenido los bancos extranjeros en conquistar posiciones en los mercados locales. Por ejemplo, los bancos argentinos y mexicanos son más pequeños que los brasileños. Entre los diez bancos latinoamericanos más grandes en diciembre de 1997, había seis brasileños, tres argentinos y sólo uno mexicano (cuadro 7). Aparte de sus amplias redes de agencias bancarias, los bancos brasileños emplean sofisticadas tecnologías de transferencia electrónica de fondos y de gestión de recursos. Desarrolladas en un período de alta inflación, esas tecnologías los ayudarán a conservar a sus clientes, impidiendo la desintermediación financiera que afectó a los bancos argentinos y mexicanos. Igualmente esas tecnologías los colocan - sobre todo a los grandes bancos- en condiciones de competir con los bancos extranjeros presentes en el país.

En relación con los demás bancos latinoamericanos, las instituciones brasileñas se benefician también del hecho de que el sistema bancario nacional no ha atravesado por ninguna crisis profunda y generalizada en los últimos decenios. Además, las instituciones bancarias locales no son vistas con desconfianza por el público. Por el contrario, los bancos públicos atraen más clientes que los privados en los momentos en que la fragilidad financiera se acentúa.

La mayor vulnerabilidad de los bancos brasileños es el volumen de capital muy reducido en comparación con los bancos extranjeros. Esto vale también para los bancos argentinos y mexicanos. El HSBC reúne por sí solo más capital que todos los diez mayores bancos latinoamericanos (cuadro 7). En los países en que la legislación lo permite, es enorme la vulnerabilidad de los bancos nacionales a la amenaza de una adquisición (takeover) hostil por parte de las instituciones extranjeras. 


\begin{tabular}{|c|c|c|c|c|c|}
\hline \multirow{3}{*}{ Institución } & \multicolumn{5}{|c|}{$\begin{array}{l}\text { Posición de los diez mayores bancos argentinos, brasileños } \\
\text { y mexicanos en diciembre de } 1997\end{array}$} \\
\hline & \multirow[t]{2}{*}{ País } & \multirow[t]{2}{*}{ Propiedad del capital } & \multirow{2}{*}{$\begin{array}{l}\text { Capital (millones } \\
\text { de dólares) }\end{array}$} & \multicolumn{2}{|c|}{ Clasificación } \\
\hline & & & & América Latina $^{\mathrm{a}}$ & Mundial $^{\mathrm{b}}$ \\
\hline Banco do Brasil & Brasil & Público & 5562 & 1 & 63 \\
\hline Bradesco & Brasil & Privado & 5481 & 2 & 65 \\
\hline Itaú & Brasil & Privado & 3893 & 3 & 99 \\
\hline Unibanco & Brasil & Privado & 2373 & 4 & 145 \\
\hline Banespa & Brasil & Público & 2350 & 5 & 147 \\
\hline Nación Argentina & Argentina & Público & 2002 & 6 & 166 \\
\hline Banamex & México & Privado & 1790 & 7 & 181 \\
\hline Bancomer & México & Privado & 1659 & 8 & 196 \\
\hline Banco Real & Brasil & Privado & 1581 & 9 & 200 \\
\hline Provincia de Buenos Aires & Argentina & Público & 1223 & 10 & 238 \\
\hline \multicolumn{6}{|l|}{ Comparados con: } \\
\hline Corporation (HSBC) & Reino Unido & Privado & 27392 & - & 1 \\
\hline Citicorp & Estados Unidos & Privado & 22211 & - & 4 \\
\hline ABN-Amro & Países Bajos & Privado & 15864 & - & 8 \\
\hline Nations Bank & Estados Unidos & Privado & 13599 & - & 13 \\
\hline Santander & España & Privado & 7952 & - & 40 \\
\hline Bank of Nova Scotia & Canadá & Privado & 6820 & - & 49 \\
\hline Banco Bilbao Vizcaya & España & Privado & 6800 & - & 50 \\
\hline
\end{tabular}

Fuente: The Banker (1998).

a Los 25 mayores bancos según su capital. Esta clasificación excluye las subsidiarias íntegramente de bancos extranjeros.

b Los 1000 mayores bancos según su capital.

\section{IV}

\section{Conclusiones}

Como se ha intentado demostrar, el impacto de las inversiones extranjeras (de cartera y directas) sobre los mercados financieros latinoamericanos se diferencia en función de los distintos grados de apertura financiera, de las características institucionales específicas de cada sistema financiero nacional, así como de las distintas opciones de gestión macroeconómica de las corrientes externas.

En los tres países analizados, el perfil de las inversiones de cartera en los mercados financieros locales estuvo configurado por las distintas políticas de apertura financiera, en las que influyó, entre otros factores, la estrategia de estabilización monetaria, la cual también determinó los diferentes grados de libertad de la gestión macroeconómica en el manejo de las corrientes de capital. En la Argentina, la adopción de un plan de estabilización basado en un régimen de junta monetaria (currency board) implicó una apertura finan- ciera total de la economía. En México y Brasil los programas antiinflacionarios no exigían la liberalización completa de la cuenta de capitales y la adopción de la convertibilidad monetaria. Además, el régimen cambiario y monetario vigente después de la estabilización (bandas cambiarias) les permitió algún radio de maniobra para la gestión macroeconómica de las corrientes de capital, mediante la ampliación de la banda de fluctuación del tipo de cambio con el objetivo de desalentar la afluencia de corrientes de corto plazo, y la esterilización del ingreso de capitales mediante la emisión de títulos públicos.

Los efectos de la apertura de los mercados financieros locales se concentraron en segmentos distintos - en la Argentina, en el mercado monetario; en México, en el mercado de títulos públicos; y en el Brasil, en el mercado secundario de acciones. Por este motivo, los impactos de la inversión extranjera directa so- 
bre los sistemas financieros nacionales y, por ende, sobre la economía en su conjunto, se diferenciaron tanto en cuanto a los momentos de abundancia como en lo que toca al cambio de dirección de esas corrientes. Los desequilibrios que causa una fuga de capitales provocada por el rescate súbito de los depósitos bancarios de no residentes (que en general sirven para financiar operaciones de crédito interno) son, potencialmente, mucho más perjudiciales que los asociados a la venta masiva de acciones por inversionistas extranjeros, ya que en América Latina la integración entre los mercados de crédito y los accionarios (ya sea mediante participaciones cruzadas o debido a la utilización de esos documentos como garantía de los préstamos) es tenue. Siendo así, las repercusiones de la apertura financiera sobre las economías periféricas también dependen de las características estructurales de los sistemas financieros nacionales.

A pesar de los rasgos comunes de las estrategias de política económica de los tres países analizados - planes de estabilización con ancla cambiaria, apertura financiera y comercial, privatización, etc. - las experiencias de Argentina, México y Brasil en el decenio de 1990 revelan que queda espacio de maniobra todavía para las políticas nacionales en el contexto actual de la globalización financiera. Esas políticas pueden atenuar los riesgos financieros asociados con la inversión extranjera de cartera, ya que tales riesgos guardan relación directa con la naturaleza de esas corrientes y con sus plazos de vencimiento.

En lo que se refiere a los sistemas financieros locales, se advierte una tendencia hacia la importancia creciente de las instituciones extranjeras en los mercados financieros de los tres países analizados. Esa tendencia resulta, sobre todo, de las medidas de liberalización adoptadas por los gobiernos para capitalizar los debilitados sistemas financieros bancarios. La mayor participación extranjera obedece también a las estrategias de competencia de los propios bancos, que tratan de conquistar nuevas fuentes de lucro y de fortalecer sus posiciones en mercados cada vez más globalizados.

Al contrario de lo que sostienen los organismos multilaterales que abogan por la apertura del sistema financiero de los países en desarrollo a las instituciones extranjeras, no existe ninguna garantía previa de que la entrada de nuevos competidores se traducirá en la reducción de las tarifas y de los costos del crédito. La entrada de nuevas instituciones y la ampliación de la presencia extranjera en los países analizados se basa en la motivación básica de obtener grandes ganancias.
En ese sentido, aunque posean ventajas competitivas frente a los bancos nacionales, es difícil imaginar que las instituciones extranjeras se privarían de altos ingresos promoviendo rebajas de tarifas y márgenes. De producirse iniciativas de ese tipo, se trataría más bien de estrategias de comercialización de corto plazo que de la expresión de una política duradera. Además, la competencia de precios es sólo una de las varias estrategias competitivas de una institución bancaria. Los posibles impactos positivos de la mayor presencia extranjera en el costo de los servicios bancarios y las condiciones de financiamiento de las economías, así como en el mejoramiento de los servicios bancarios prestados a la población, están todavía por verse. Siguen siendo una incógnita, que sólo el futuro podrá despejar.

Sin embargo, existe un aspecto que merece señalarse como consecuencia benéfica de la mayor participación de la banca extranjera: el aumento de la solidez patrimonial de los sistemas bancarios nacionales. No cabe duda de que las instituciones más fuertes tienen mayor capacidad de absorber los choques macroeconómicos, reduciendo así la posibilidad de crisis sistémicas.

No obstante, la posibilidad de una migración de recursos hacia los bancos extranjeros - si ocurriera una fuga de capitales, como medida de seguridad por parte del público ante la amenaza de insolvencia de algún gran banco privado nacional- sin duda tendría efectos perjudiciales sobre la gestión macroeconómica en países como Brasil y México, que todavía tienen una relativa soberanía monetaria ya que no adoptaron el régimen de junta monetaria. En un cuadro de predominio de las instituciones extranjeras, la autoridad monetaria tendría suma dificultad en manejar las condiciones de liquidez del sistema. En 1995 las autoridades brasileñas enfrentaron una situación de esa naturaleza, cuando el alza de la tasa de interés interno en respuesta a las reacciones adversas a la crisis mexicana afectó profundamente el sistema bancario local. Con la elevación de los intereses y el crecimiento de la morosidad, los bancos se volvieron más selectivos, lo que dificultó el refinanciamiento de los deudores no financieros y de las instituciones bancarias más dependientes del movimiento interbancario. En esa ocasión, la preferencia por la liquidez de los bancos privados, nacionales y extranjeros, anuló los esfuerzos del Banco Central por reactivar el mercado interbancario. Sin el concurso de los principales bancos públicos, los que desempeñan el papel de prestamistas de última instancia para los bancos en dificultades, la fragilidad financiera del sistema bancario podría haberse agravado, 
desatando una crisis generalizada. Esta experiencia sugiere la importancia de que los países en desarrollo posean un sistema bancario mixto, en el cual los bancos públicos bien administrados puedan convivir con los bancos privados nacionales y extranjeros, y presten su auxilio para la consecución de las metas de la política gubernamental.

(Traducido del portugués)

\section{Bibliografía}

Akyüz, Y. (1992): On Financial Openness in Developing Countries, Ginebra, Conferencia de las Naciones Unidas sobre Comercio y Desarrollo (UNCTAD).

Armella, P. (1993): El camino mexicano de la transformación económica, México, D.F., Fondo de Cultura Económica (FCE).

Banxico (Banco de México) (varios años): Informe anual, México, D.F.

(1996): Informe anual, México, D.F.

(1997): Informe anual, México, D.F.

(1998): Informe anual, México, D.F.

Blejer, L. y G. Rozenwurcel (1997): El sistema bancario argentino en los noventa: de la profundización financiera a la crisis sistémica, Desarrollo económico, vol. 37, № 146, Buenos Aires, Instituto de Desarrollo Económico y Social (IDES).

Borio, E. y R. Filosa (1995): The changing borders of banking: trends and implications, The Financial Landscape: Forces Shaping the Revolution in Banking. Risk Managements and Capital Markets, París, Organización de Cooperación y Desarrollo Económicos (OCDE).

Bouzas, R. y R. Ffrench-Davis (1998): La globalización y la gobernabilidad de los países en desarrollo, Revista de la CEPAL, número extraordinario, LC/G.2037-P, Santiago de Chile, Comisión Económica para América Latina y el Caribe (CEPAL), octubre.

Bovespa (Bolsa de Valores de São Paulo) (varios números): Revista BOVESPA, São Paulo.

Caro Razú, E.C. (1994): Acceso a los mercados internacionales de capital y desarrollo de instrumentos financieros: el caso de México, Serie Financiamiento del Desarrollo, $\mathrm{N}^{\circ} 18$, Santiago de Chile, CEPAL, junio.

CEPAL (1995): América Latina y el Caribe: políticas para mejorar la inserción en la economía mundial, LC/G.1800/Rev.1-P, Santiago de Chile, Publicación de las Naciones Unidas, $\mathrm{N}^{\circ}$ de venta S.95.II.G.6.

Chesnais, F. (1994): La mondialisation du capital, París, Syrois.

Comité de Basilea de Supervisión Bancaria (1995): 65th Annual Report, Basilea, junio.

Conger, L. (1998): Santander's Latin America crusade, Institutional Investor, vol. XXIV, $\mathrm{N}^{\circ} 1$. Nueva York, Institutional Investor Inc., enero.

(1999): Participação estrangeira no México deve crescer, Gazeta mercantil Latino-Americana, año 4, Nº 155, 12 al 18 de abril.

Cypher, J. (1996): Mexico: Financial fragility or structural crisis?, Journal of Economic Issues, vol. XXX, $\mathrm{N}^{\circ} 2$, Sacramento, California, Association for Evolucionary Economics, junio.

Del Villar, R. y otros (1997): Experiencia internacional en la resolución de crisis bancarias, Documento de investigación, $\mathrm{N}^{\circ}$ 9708, México, D.F., BANXICO, diciembre.

Fanelli, J.M. y J. Machinea (1997): O movimento de capitais na Argentina, R. Ffrench-Davis y S. Griffith-Jones (orgs.), Os fluxos financeiros na América Latina: um desafio ao progresso, Río de Janeiro, Editora Paz e Terra.

Feldman, E. y J. Sommer (1984): Crisis financiera y endeudamiento externo: consecuencias de la política económica del pe- ríodo 1976-1981, Buenos Aires, Centro de Economía Transnacional (CET).

Ferrari, A. (1998): O plano de convertibilidade argentino, Campinas, Brasil, Universidad Estadual de Campinas, Instituto de Economía, tesis de maestría.

Ferreira, C.K.L. y otros (1998): O formato institucional do sistema monetário e financeiro: um estudo comparado, M. A. M. Cintra y M.C. P. Freitas (orgs.) Transformações institucionais dos sistemas financeiros: um estudo comparado, São Paulo, Fundación de Desarrollo Administrativo.

Ffrench-Davis, R. y S. Griffith-Jones (orgs.) (1997): Os fluxos financeiros na América Latina: um desafio ao progresso, Río de Janeiro, Editora Paz e Terra.

Folkerts-Landau, D., D.J. Mathieson y G.J. Schinasi (1997): International Capital Markets: Developments, Prospects and Key Policy Issues, Washington, D.C., Fondo Monetario Internacional (FMI), noviembre.

Freitas, M.C.P. (1997): Concurrence bancaire, spéculation et instabilité financière: une lecture hétérodoxe de l'évolution récente du système financier international, Villetaneuse, Université de Paris, XIII, tesis de doctorado.

(1999): Abertura do sistema bancário brasileiro ao capital estrangeiro, M.C.P. Freitas (coord.), Abertura externa e sistema financeiro, São Paulo, Fundación de Desarrollo Administrativo/Fundación de Amparo y Pesquisa del Estado de São Paulo/Instituto de Investigación Económica Aplicada (FUNDAP/FAPESP/IPEA).

Freitas, M.C. y D.M. Prates (1999): Captação de recursos externos, en M.C.P. Freitas (coord.), Abertura externa e sistema financeiro, São Paulo, Fundación de Desarrollo Administrativo/Fundación de Amparo y Pesquisa del Estado de São Paulo/Instituto de Investigación Económica Aplicada (FUNDAP/FAPESP/IPEA).

Goldestein, M. y P. Turner (1996): Banking Crisis in Emerging Economies: Origins and Policy Options, BIS economic paper, $\mathrm{N}^{\circ} 46$, Basilea, Comité de Basilea de Supervisión Bancaria, octubre.

Griffith-Jones, S. (1996): La crisis del peso mexicano, Revista de la CEPAL, $\mathrm{N}^{\circ}$ 60, LC/G.1943-P, Santiago de Chile, CEPAL.

Gurría, J. (1997): Fluxos de capital: o caso do México, R. FfrenchDavis y S. Griffrith-Jones (comp.), Os fluxos financeiros na América Latina: um desafio ao progresso, Rio de Janeiro, Editora Paz e Terra.

KPMG Peat Marwick (1998): Pesquisa internacional sobre indústria bancária e de seguros, São Paulo, Federação Brasileira das Associações de Bancos, septiembre.

Machinea, J.L. (1996): La crisis financiera argentina de 1995: causas, características y lecciones, Buenos Aires, mimeo.

Meyer, A. (1997a): Notas sobre a economia argentina, Brasília, Ministério da Fazenda, Secretaria de Assuntos Internacionais. (1997b): Notas sobre a economia mexicana, Brasília, Ministério da Fazenda, Secretaria de Assuntos Internacionais.

Palomino, A. (1997): Surgimiento y desarrollo de los grupos financieros en México, serie Financiamento del Desarrollo, $\mathrm{N}^{\circ} 41$, Santiago de Chile, CEPAL. 
Prates, D.M. (1997): Abertura financeira e vulnerabilidade externa: a economia brasileira na década de 90, Campinas, Brasil, Universidad Estadual de Campinas, Instituto de Economía, tesis de maestría.

(1999): Investimentos de portfólio no mercado financeiro doméstico, en M.C.P. Freitas (coord.), Abertura externa e sistema financeiro, São Paulo, Fundación de Desarrollo Administrativo/IPEA, por publicarse.

Rozenwurcel, G. y R. Fernández (1994): El fortalecimiento del sector financiero en el proceso de ajuste: el caso argentino, R. Frenkel (ed.), El fortalecimiento del sector financiero en el proceso de ajuste: liberalización y regulación, Buenos Aires, Red de Centros de Investigación Económica Aplicada.

Skiles, M. (1991): Stabilization and Financial Sector Reform in Mexico, Research paper $\mathrm{N}^{\circ} 9125$, Nueva York, Banco de la Reserva Federal de Nueva York.

Souza, F. (1993): O novo regime cambial brasileiro e suas consequências para a política econômica, Texto de Discussão IPEA, $\mathrm{N}^{\circ} 18$, Brasília, IPEA, noviembre.
Taylor, R. (1997a): Back from the brink, The Banker, Londres, FT Finance, agosto.

(1997b): Surfing a rising tide, The Banker, Londres, FT Finance, agosto.

(1999): Peso fights back, The Banker, Londres, FT Finance, febrero.

The Banker (1997a): Latin notes: Mexico ends bank subsidies; Brazil opens up, Londres, FT Finance, octubre.

(1997b): Latin notes: Competitions heats up in Brazil; consolidation continues in Argentina, Londres, FT Finance, septiembre.

(1998): Top 1000 world banks, Londres, FT Finance, julio.

The Economist (1997): Flexionando os músculos na América Latina, Londres, The Economist Newspaper Limited, 11 de julio. (1998): Europe's lovesick bankers, Londres, The Economist Newspaper Limited, 10 de enero.

Warner, A. (1995): On the Lima trail, The Banker, Londres, FT Finance, octubre.

(1998): Latin fever catches on, The Banker, Londres, FT Finance, enero. 